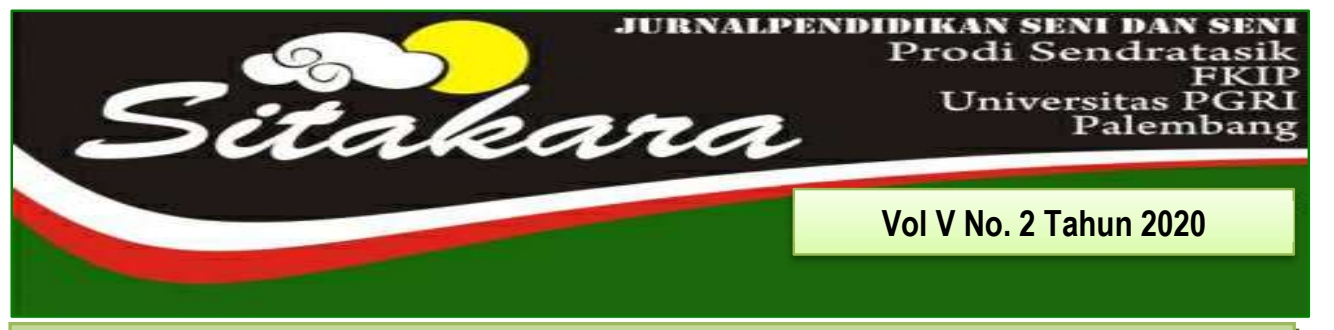

FUNGSI DAN MAKNA BHAJAN PADA UPACARA AGAMA HINDU DI KUIL SHRI MARIAMMAN KOTA MEDAN

(Agung Suharyanto, dkk)

KESENIAN SRANDUL DALAM UPACARA BERSIH DESA BULU KALURAHAN KARANGMOJO KECAMATAN KARANGMOJO KABUPATEN GUNUNGKIDUL YOGYAKARTA

(Supriyanto)

FUNGSI DAN MAKNA LAGU GUBANG DALAM UPACARA SIAR MAMBANG PADA MASYARAKAT TANJUNGBALAI

(Theo henry tua siagian ${ }^{1}$, pulumun p. Ginting ${ }^{2} \&$ wiflihani)

FUNGSI TARI MAPAK ADAT MUARA KUANG SEBAGAI TARI SAMBUT

(Nadia Rahma Aprilia', Dessy Wardiah², Treny Hera ${ }^{3}$ )

MAKNA SIMBOLIK RAGAM HIAS PADA RUMAH LIMAS PALEMBANG

(Ferri Hidayad ${ }^{1}$ Decky Kunian ${ }^{2}$ )

GAYA MUSIK SAHILIN DALAM KESENIAN MUSIK BATANGHARI SEMBILAN DI KOTA PALEMBANG

(Feri Firmansyah)

TRANSPOSISI TTI (TRANSFER, TRANSLATION, IMITATE) DALAM PEMBELAJARAN NOTASI MUSIK MELALUI SCORE CREATOR

(A Heryanto ${ }^{1}$ Dedy Firmansyah ${ }^{2}$ )

RASE TAK SERUPE MUSIK MELAYU TRADISI DENGAN PENGEMBANGAN MUSIK MODERN DALAM RUANG PERTUNJUKAN KOMPOSISI MUSIK NUSANTARA (Rio Eka Putra)

BENTUK SYAIR LAGU DALAM PERTUNJUKAN SYAROFAL ANAM DI PEDESTRIAN S UDIRMAN KOTA PALEMBANG

(Nofroza Yelli ${ }^{1}$ Deria Sepdwiko² ${ }^{2}$

"Betenun" Sebuah Wujud Proses Kreatif Mahasiswa Seni Pertunjukan Universitas PGRI PALEMBANG

(Nurdin $^{1}$ Naomi Diah Budi Setyaningrum ${ }^{2}$ ) 
DAFTAR ISI

FUNGSI DAN MAKNA BHAJAN PADA UPACARA AGAMA HINDU DI KUIL 1-15 SHRI MARIAMMAN KOTA MEDAN

(Agung Suharyanto, dkk)

KESENIAN SRANDUL DALAM UPACARA BERSIH DESA BULU KALURAHAN

$16-26$

KARANGMOJO KECAMATAN KARANGMOJO KABUPATEN GUNUNGKIDUL YOGYAKARTA

(Supriyanto)

FUNGSI DAN MAKNA LAGU GUBANG DALAM UPACARA SIAR MAMBANG 27-39 PADA MASYARAKAT TANJUNGBALAI

(Theo henry tua siagian ${ }^{1}$, pulumun $p$. Ginting ${ }^{2} \&$ wiflihani)

FUNGSI TARI MAPAK ADAT MUARA KUANG SEBAGAI TARI SAMBUT

40-52

(Nadia Rahma Aprilia', Dessy Wardiah², Treny Hera')

MAKNA SIMBOLIK RAGAM HIAS PADA RUMAH LIMAS PALEMBANG

53-61

(Ferri Hidayad ${ }^{1}$ Decky Kunian ${ }^{2}$ )

GAYA MUSIK SAHILIN DALAM KESENIAN MUSIK BATANGHARI SEMBILAN DI $\quad 62-76$ KOTA PALEMBANG

(Feri Firmansyah)

TRANSPOSISI TTI (TRANSFER, TRANSLATION, IMITATE) DALAM 77-85 PEMBELAJARAN NOTASI MUSIK MELALUI SCORE CREATOR (A Heryanto ${ }^{1}$ Dedy Firmansyah ${ }^{2}$ )

RASE TAK SERUPE MUSIK MELAYU TRADISI DENGAN PENGEMBANGAN MUSIK MODERN DALAM RUANG PERTUNJUKAN KOMPOSISI MUSIK NUSANTARA

(Rio Eka Putra)

BENTUK SYAIR LAGU DALAM PERTUNJUKAN SYAROFAL ANAM DI PEDESTRIAN SUDIRMAN KOTA PALEMBANG

(Nofroza Yelli ${ }^{1}$ Deria Sepdwiko ${ }^{2}$ )

"BETENUN" SEBUAH WUJUD PROSES KREATIF MAHASISWA SENI

$109-120$ PERTUNJUKAN UNIVERSITAS PGRI PALEMBANG

(Nurdin ${ }^{1}$ Naomi Diah Budi Setyaningrum ${ }^{2}$ )

86-95 


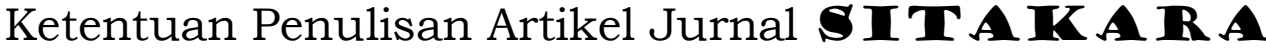

1. Naskah berbahasa Indonesia bertemakan Seni Budaya yang meliputi hasil penelitian pengajaran seni budaya, cabang seni, dan kebudayaan.

2. Naskah harus asli dan belum pernah dimuat dalam media lain. Naskah dapat berupa hasil penelitian perorangan atau kelompok.

3. Naskah ditulis dengan cara-cara yang sesuai dengan ketentuan penulisan artikel ilmiah menggunakan bahasa Indonesia yang baku, berupa ketikan, beserta soft line dalam CD-RW atau dengan mengirimkan email pada redaksi Jurnal SITAKA RA dengan alamat email: jurnalsitakarasendratasik@yahoo.com, spasi 1,5 jenis huruf Arrial Narrow ukuran 12, dengan panjang naskah antara 8-15 halaman pada kertas A4.

4. Artikel hasil penelitian memuat:

JUDUL

Nama Penulis

Abstrak

A. PENDAhuluan

B. METODE PENELITIAN

C. HASIL DAN PEMBAHASAN

D. SIMPULAN

5. Artikel kajian konseptual memuat:

JUDUL

Nama Penulis

Abstrak

PENDAHULUAN
: XXX (HURUF KAPITAL)

: (disertai jabatan dan institusi)

: (Bahasa Indonesia yang memuat 100150 kata diikuti kata kunci, dengan jenis huruf Arrial Narrow dan ukuran huruf 11 spasi tunggal serta dicetak miring)

: (Memuat latar belakang masalah, tinjauan pustaka secara ringkas, masalah penelitian dan tujuan penelitian)

: (Berisi simpulan)

\section{: XXX (HURUF KAPITAL)}

: (disertai jabatan dan institusi)

: (Bahasa Indonesia yang memuat 100150 kata diikuti kata kunci, dengan jenis huruf Arrial Narrow dan ukuran huruf 11 serta dicetak miring)

: (Memuat latar belakang masalah, tinjauan pustaka secara ringkas, 
Sub Judul

Sub Judul

SIMPULAN

DAFTAR PUSTAKA masalah penelitian dan tujuan

penelitian)

: Sesuai dengan kebutuhan (tanpa

numbering)

: (Berisi simpulan dan saran)

: (Berisi pustaka yang dirujuk dalam uraian naskah

6. Referensi sumber dalam teks artikel ditulis dengan menggunakan side note, contoh: (Jalalluddin, 1991:79); (Taufik, 2005;350); (Hamid dan Madjid, 2011:43). Sementara penulisan daftar pustaka disusun dengan ketentuan. Nama Pengarang. Tahun Terbit. Judul (dicetak miring). Kota Terbit: Nama Penerbit. Contoh: Koentjaraningrat. 2010. Manusia dan Kebudayaan Di Indonesia. Jakarta: Djambatan.

Daftar pustaka hanya memuat pustaka/sumber yang dirujuk dalam uraian dan disusun menurut abjad, tanpa nomor urut.

7. Naskah yang dimuat akan disunting kembali oleh redaksi tanpa mengubah isinya.

8. Naskah yang ditolak (tidak bisa dimuat) akan dikirim kembali ke penulis dengan pemberitahuan tertulis dari redaksi atau alamat email.

9. Penulis yang naskahnya dimuat akan mendapatkan 1 (satu) majalah nomor yang bersangkutan.

10. Contact Person: Treny Hera (085357344704) dan Mainur (081373165553). 


\title{
MAKNA SIMBOLIK RAGAM HIAS PADA RUMAH LIMAS PALEMBANG
}

\author{
Oleh: \\ Ferri Hidayad $^{1}$ Decky Kunian ${ }^{2}$ \\ (FKIP Universiyas PGRI.Palembang) \\ Email: ferri6591@gmail.com
}

\begin{abstract}
ABSTRAK
Rumah Limas atau rumah Bari merupakan arsitektur tradisional Palembang yang paling terkenal karena corak dan bentuk serta kepadatan seni ukir di dalam rumah tersebut dan disertai kemegahannya. Semua ini menggambarkan tingginya tingkat kebudayaan suku bangsa yang memilikinya. Disebut Limas karena mengandung makna "lima" dan emas kelima emas itu berturutturut memiliki arti : (1) keagungan dan kebesaran, (2) rukun dan damai, (3) memiliki adab sopan santun, (4) aman, subur sentosa, (5) makmur sejahtera Motif yang mengacu pada tumbuhtumbuhan memiliki fungsi sakral atau simbol, fungsi sakral atau simbolik yang melekat pada ornamen dalam rupa tumbuh-tumbuhan dilatari oleh konsepsi pandangan masyarakat Palembang. Maknanya bahwa pemilik rumah Limas mempunyai jiwa besar, memiliki strata sosial yang tinggi dengan ekonomi yang tinggi, serta memiliki kemakmuran.
\end{abstract}

\section{Kata Kunci: Makna Simbolik, Ragam Hias, Rumah Limas}

\section{A.PENDAHULUAN}

Seni adalah realisasi dari usaha manusia untuk menciptakan yang indahindah. Keindahan itu terdapat pada objek dan subjek pada benda seninya atau pada orang melihat, atau justru berada ditempat yang lain lagi, karena bagi seorang plato keindahan terdapat di dalam pikiran yang murni manusia yang ideal. Bagi Plato keindahan tidak tergantung pada rasa suka atau tidak suka sesorang secara individual (Soedarso, 2006:11), sedangkan menurut Dharsono seni merupakan

$$
\begin{aligned}
& \text { kebudayaan yang tumbuh dan } \\
& \text { berkembang sejajar dengan } \\
& \text { perkembangan manusia selaku } \\
& \text { penggubah dan penikmat seni. } \\
& \text { Kebudayaan merupakan warisan yang } \\
& \text { harus kita lestarikan dan kita } \\
& \text { kembangkan agar tidak punah, dengan } \\
& \text { memiliki kebudayaan kita memiliki ciri } \\
& \text { khas tersendiri di mata dunia. } \\
& \text { Kebudayaan merupakan keseluruhan } \\
& \text { sistem gagasan, tindakan dan hasil karya } \\
& \text { manusia dalam kehidupan masyarakat } \\
& \text { (2006:26). }
\end{aligned}
$$


Koentjaraningrat kesenian tradisional, yang lebih dikenal dengan merupakan salah satu unsur budaya manusia. Kita dapat merasakan dalam pengalaman hidup sehari-hari, betapa kita sangat membutuhkan sarana berekspresi dan menikmati keindahan dalam berbagai bentuk. Kesenian juga berakar pada adat istiadat dan diwariskan secara turun-temurun (1990). sedangkan menurut Sardono (dalam Sartono 2007:01) kesenian itu memiliki nilai estetis (indah) yang di sukai oleh manusia dan mengandung ide-ide yang dinyatakan dalam bentuk aktivitas atau rupa sebagai lambang. Jadi dapat disimpulkan bahwa kesenian merupakan unsur kebudayaan yang harus kita lestarikan dan kembangkan sebagai bentuk warisan yang mengandung nilai estetika.

Salah satunya di Palembang yang merupakan ibu kota Sumatera Selatan, banyak sekali menyimpan aset budaya dan kebudayaan. Disamping kebudayaan Palembang juga antara lain kesenian kuliner, dan kerajinan khas Palembang. Palembang mempunyai beragam kekayaan budaya yang sangat mengagumkan dan menakjubkan. Salah satu peninggalan budaya tersebut dalam bidang arsitektur ialah bangunan

Rumah Limas. Rumusan arsitektur tradisional menurut pendapat Ali Mansur dalam Sukanti (1993:3) adalah suatu bangunan yang bentuk struktur, fungsi, ragam hias dan cara pembuatannya, diwariskan secara turun-temurun, serta dapat dipakai untuk dapat melakukan aktivitas kehidupan dengan sebaikbaiknya.

Rumah Limas atau rumah Bari merupakan arsitektur tradisional Palembang yang paling terkenal karena corak dan bentuk serta kepadatan seni ukir di dalam rumah tersebut dan disertai kemegahannya. Semua ini menggambarkan tingginya tingkat kebudayaan suku bangsa yang memilikinya. Rumah Limas adalah bangunan khas para penguasa (patih, bupati, adi pati, dan para pangeran), di daerah pada saat mereka berkuasa, dengan demikian pada umumnya mempunyai keterkaitan sejarah dengan kota Palembang atau setidak-tidaknya dengan penguasa setempat yang dihormati oleh warga sekitarnya (Siswanto, 1997:3).

Dari pemahaman di atas tentunya sangat menarik jika penulis melakukan penelitian lanjutan dalam 
melihat makna simbolis pada ragam hias rumah Limas Palembang tersebut dengan tujuan untuk meperkenalkan secara luas bahwa dengan adanya tulisan ini masyarakat dapat lebih mengetahui dan lebih mengenal lagi mengenai Rumah Limas Palembang

\section{B.METODELOGI PENELITIAN}

Data yang digunakan dalam penelitian ini ada dua, yaitu data primer dan data sekunder. Lebih jelasnya dapat diuraikan sebagai berikut: Data Primer dalam penulisan ini diambil dengan menggunakan observasi dan wawancara yang dijabarkan sesuai dengan masalah yang ada pada penelitian. Data skunder merupakan data pendukung yang melengkapi data primer. Data sekunder yang diambil dalam penelitian ini adalah berupa buku-buku, majalah, koran dan foto- foto yang berkaitan dengan masalah berupa foto-foto selama penelitian. Teknik pengumpulan data yang digunakan pada penelitian ini antara lain: studi pustaka, observasi, wawamcara dan dokumentasi.

Analisis data yang digunakan dalam penelitian ini adalah Model analisis Miles dan Huberman (dalam Sugiyono, 2015:246) yang mencangkup tiga kegiatan yang bersamaan reduksi data, penyajian data dan penarikan kesimpulan.

1. Reduksi Data (Data Reduction) Mereduksi data berarti merangkum, memilih hal-hal yang pokok, memfokuskan pada hal-hal yang penting, dicari tema dan polanya.

2. Penyajian Data (Data Display) Menyajikan data yaitu penyusunan sekumpulan informasi yang memberi kemungkinan adanya penarikan kesimpulan dan penarikan tindakan. Dalam penelitian kualitatif, penyajian data bisa dilakukan dalam bentuk uraian singkat, bagan, hubungan antar kategori, atau sejenisnya. Dalam penelitian ini, secara teknis data-data akan disajikan dalam bentuk teks naratif, tabel, dan foto.

3. Penarikan Kesimpulan (Conclusion Drawing) Kesimpulan dalam penelitian kualitatif adalah merupakan temuan baru yang sebelumnya belum pernah ada. Dengan demikian kesimpulan dalam penelitian kualitatif mungkin dapat menjawab rumusan masalah yang dirumuskan sejak awal, tetapi mungkin juga tidak karena masalah dan rumusan masalah dalam penelitian kualitatif masih bersifat sementara dan akan 
berkembang setelah penelitian berada dilapangan. Secara teknis proses penarikan kesimpulan dalampenelitian ini akan dilakukan dengan cara mendiskusikan data-data hasil temuan dilapangan dengan teori-teori yang dimasukan dalam bab tinjauan pustaka.

\section{HASIL DAN PEMBAHASAN}

Limas mengandung makna "lima" dan emas kelima emas itu berturut-turut memiliki arti : keagungan dan kebesaran, (2) rukun dan damai, (3) memiliki adab sopan santun, (4) aman, subur sentosa, (5) makmur sejahtera.

Hiasan pada bentuk rumah Bari pada dasarnya ada 2 macam, yaitu, hiasan yang kontruksional dan hiasan yang tidak konstruksional. Ragam hias yang terdapat pada bangunan rumah tradisional masyarakat Sumatera Selatan pada umumnya, adalah berupa flora. Flora yang banyak kita dapati sebagai hiasan pada bangunan rumah Bari, adalah macam flora yang memiliki makna suci, berwarna indah, berbentuk halus simetris atau yang serba estetis. Adapun macam flora yang diketengahkan dalam uraian ini, meliputi batang, daun, bunga, buah, dan ujung pohon-pohonan. Ragam hias kedua yaitu bentuk alam, macam ragam hias yang menggambarkan perwujudan alam secara stilisasi.

Ragam hias atau ornamen pada Rumah Limas Palembang sangat beranekaragam. Kehadiran ornamen pada rumah Limas Palembang merupakan sebuah bentuk alkulturasi budaya dari unsur-unsur kebudayaan Hindu-Budha, Islam dan kebudayaan lokal yang terpresentasikan kedalam sebuah ornamentasi, yang mencerminkan keindahan dengan memunculkan simbol-simbol sebagai ungkapan keindahan. Ornamen rumah Limas Palembang yang dipakai adalah bahan kayu maka teknik yang dipakai pahat dan ukir. Motif-motif yang diterapkan pada ornamen rumah Limas Palembang bersifat florati dekoratif.

Motif ornamen rumah Limas Palembang berbentuk flora atau tumbuhtumbuhan dan mengacu pada bentuk alam seperti daun, bunga, buah, serta pohon. Keberadaan motif tumbuhtumbuhan dalam kebudayaan ornamentasi Palembang, karena mendapatkan sugesti dari alam. Pola tatanan dalam kehidupan masyarakat Palembang dianalogikan tercermin pada 
ornamen rumah Limmas Palembang.

Motif ornamen pada rumah Limas

Palembang digambarkan dengan bentuk daun. Pada dasarnya motif tumbuhtumbuhan diwujudkan pada keseluruhan ornamen. Jenis motif ornamen rumah Limas Palembang di antaranya motif bunga teratai, motif bunga mawar, motif bunga melati, bunga cempaka dan bunga tanjung, motif buah srikaya, jenis motif berupa tanaman yang merambat disebut juga dengan motif sulur-suluran, serta motif anak bambu disebut deng pucuk rebung. Ornamen ukir pada rumah Limas Palembang dimanifestasikan melalui motif tumbuh-tumbuhan. Adanya motif-motif seni ukir dari bentuk ini cenderung kepada adanya Islam untuk melarang menggambarkan mahkluk hidup baik berupa manusia maupun hewan.

Dapat dipahami bahwa makna ragam hias ukiran pada rumah Limas Palembang, yaitu keberadaan ragam hias pada rumah Limas Palembang sebagai sebuah simbol mencerminkan kebudayaan masyarakat Sumatera Selatan khususnya masyarakat Palembang. Kajian simbol ornamen rumah Limas Palembang ini merupakan penggalian akar kebudayaan masyarakat
Palembang yang didasari oleh struktur sosial dan kepercayaan.

Motif yang mengacu pada tumbuh-tumbuhan memiliki fungsi sakral atau simbol, fungsi sakral atau simbolik yang melekat pada ornamen dalam rupa tumbuh-tumbuhan dilatari oleh konsepsi pandangan masyarakat Palembang. Motif Bunga Teratai dipandang sebagai tanaman suci. Teratai atau Padma pada zaman Hindu-Budha melambangkan tempat duduk dewa tertinggi, bunga tempat keluarnya dewa-dewa, keberadaan teratai pada zaman Hindu diwujudkan menyertai penggambaran para dewa-dewa sehingga gambaran bunga teratai dikenal sebagai lambang hidup Motif ini sangat sederhana namun indah dan menarik. Berkaitan dengan motif bunga teratai pada dinding ruang tengah rumah limas, Satriawan mengatakan motif bunga teratai yang dipasang di atas simbar dan jendela melambangkan kesucian, motif ornamen yang dipakai adalah bunga teratai merah dan bunga teratai putih yang melambangkan kesucian, karena pecek lawang befungsi sebagai ventilasi maka kesegaran dan kebersihan udara (pergantian udara) diharapkan melalui celah-celah teratai tersebut. Motif bunga 
cempaka melambangkan keceriaan, semarak dan meriah. Bunga Mawar melambangkan penawar rasa sakit maupun penawar rasa rindu. Bunga melati melambangkan kebaikan, ketulusan dan ke ikhlasan. Motif bunga tanjung melambangkan seakan akan memberikan perkataan selamat datang kepada para tamu dan rumah tersebut selalu terbuka serta mengharapkan kunjungan-kunjungan. Ornamen motif buah Srikaya yang menghiasi di atas ruang tengah rumah Limas didominasi oleh stilasi daun yang berbentuk mahkota. Ornamen Buah Srikaya, melambangkan kebesaran dan kenikmatan. Hal ini ini berati bahwa pemilik rumah Limas tersebut mempunyai jiwa besar, memiliki strata sosial yang tinggi dengan ekonomi yang tinggi, serta memiliki kemakmuran (wawancara, Juli 2020).

Ornamen dengan motif daun atau sulur-suluran/lulungan, flora ini memiliki filosofis yang sangat tinggi bagi kehidupan masyarakat Palembag. Paku jenis ini memiliki dua tipe daun. Daun pertama, berada di "pusat" tumbuhtumbuhan berbentuk perisai tegak. Bentuknya yang demikian, menyebabkan daun ini menyerupai mahkota, daun tipe kedua membentuk menjadi sulur-suluran memiliki filosofis sebagai tindakan mengayomi, melindungi, dan memberikan keteduhan kepada makhluk lain disekitarnya. "Motif ragam hias sulur merupakan penggambaran bahwa dalam kehidupan manusia selalu adanya hubungan berkesinambungan dan harus saling menghormati satu dengan yang lainnya. Motif tersebut memiliki nilai filosofi yang baik tentang moralitas persastuan dan kesatuan dalam hidup bermasyarakat, supaya terjalin hubungan yang harmonis dan selaras seuai dengan tujuan hidup yang dicita-citakan setiap manusia" (Wawancara, Satriawan, Juli 2020).

Motif ornamen pucuk rebung yang terdapat pada ruang luar rumah, ruangan ini terdapat di muka rumah yang disebut dengan pagar tenggalung adalah kisi-kisi yang menghiasi bagian terluarnya. Secara filosofis, kisi-kisi orang Palembang biasa menyebutnya kerang-kerang menjadi perlambang usaha pemilik rumah mempertahankan harkat dan martabat, termasuk semua hal yang berkaitan dengan rumah yang ditempatinya. Secara praktis kisi-kisi bermakna sebagai privasi. Kendati tempat "terbuka", orang yang berada di 
luar tidak dapat melihat bagian dalam rumah. Sebaliknya, penghuni rumah dapat melihat dengan bebas pemandangan yang ada di luar (wawancara: Satriawan, Juli 2020).

Bentuk yang seperti itu memiliki ciri yang khas, baik dilihat dari segi arsitektur, fungsi, maupun maknanya. Masyarakat Palembang menyebut rumah adat mereka dengan sebutan rumah Limas atau rumah Bari yang dibangun dengan bahan dasar kayu dengan konsep rumah panggung. Rumah Limas atau rumah Bari juga disebut rumah adat bagi sebuah keluarga. Sebagai rumah berukuran besar, rumah Limas juga merupakan simbol kedudukan keluarga.
Pelestarian rumah Limas sangat diperlukan dalam menjaga nilai tradisi dan budaya di Palembang. Diharapkan generasi muda setidaknya mengetahui nilai budaya yang ada di Palembang, khususnya mengenai rumah limas. Diharapkan kerja sama dinas pendidikan untuk menyebarkan dalam materi pembelajaran seni budaya di sekolahsekolah, sehingga para siswa mengenal budaya dan bisa melestarikan khususnya tentang rumah limas yang ada di Palembang.Berikut merupakan macam ragam hias yang ada pada rumah Limas Palembang, yaitu:
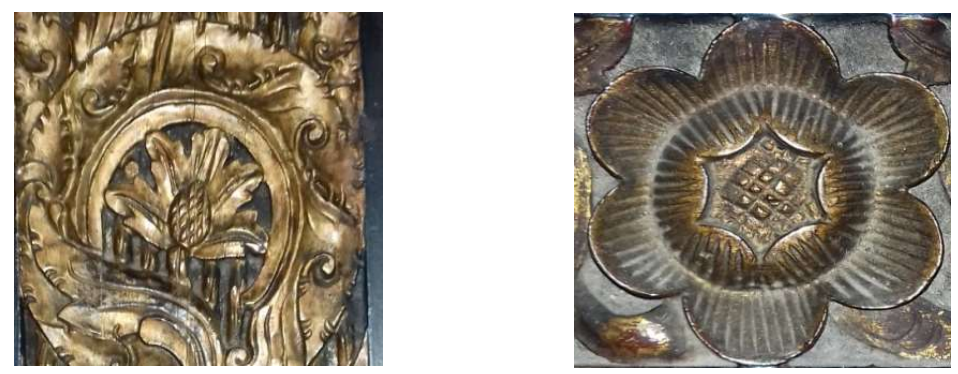

Gambar 1. Ragam Hias Ukiran Motif Bunga Teratai dan Bunga Melati
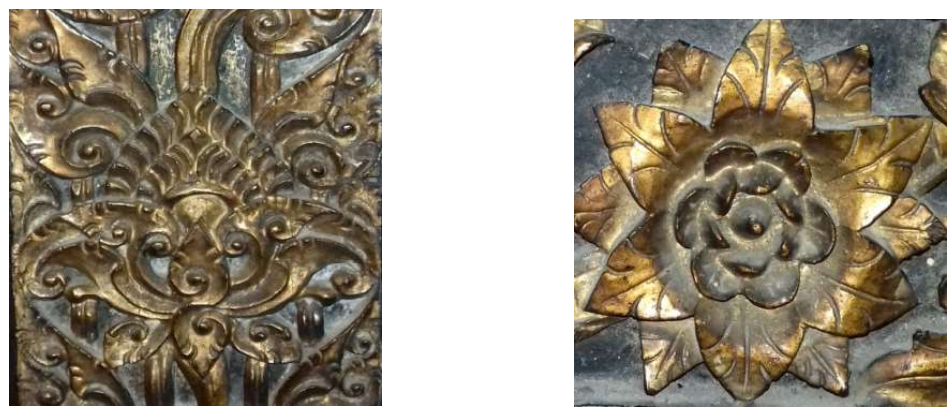

Gambar 2 : Ragam Hias Ukiran Motif Bunga Cempaka dan Bunga Mawar 

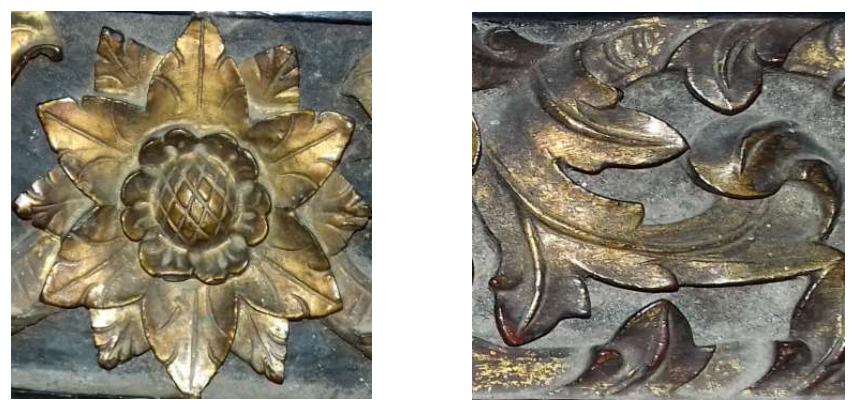

Gambar 3 : Ragam Hias Ukiran Motif Bunga Mawar dan Suluran Dau Pakis

\section{SIMPULAN}

Makna "lima" dan emas kelima emas itu berturut-turut memiliki arti : (1) keagungan dan kebesaran, (2) rukun dan damai, (3) memiliki adab sopan santun, (4) aman, subur sentosa, (5) makmur sejahtera Motif yang mengacu pada tumbuh-tumbuhan memiliki fungsi sakral atau simbol, fungsi sakral atau simbolik yang melekat pada ornamen dalam rupa tumbuh-tumbuhan dilatari oleh konsepsi pandangan masyarakat Palembang. Motif Bunga Teratai dipandang sebagai tanaman suci. Motif bunga cempaka melambangkan keceriaan, semarak dan meriah. Bunga Mawar melambangkan penawar rasa sakit maupn penawar rasa rindu. Bunga melati melambangkan kebaikan, ketulusan dan ke ikhlasan. Motif bunga tanjung melambangkan seakan akan memberikan perkataan selamat datang kepada para tamu dan rumah tersebut selalu terbuka serta mengharapkan kunjungan-kunjungan. Ornamen motif buah Srikaya yang menghiasi di atas ruang tengah rumah Limas didominasi oleh stilasi daun yang berbentuk mahkota. Ornamen Buah Srikaya, melambangkan kebesaran dan kenikmatan. Hal ini ini berati bahwa pemilik rumah Limas tersebut mempunyai jiwa besar, memiliki strata sosial yang tinggi dengan ekonomi yang tinggi, serta memiliki kemakmuran. 


\section{DAFTAR PUSTAKA}

Koentjaraningrat. Manusia dan Kebudayaan di Indonesia. Jakarta: Djembatan. 1990.

Rohendi, Tjetjep. Ekspresi Seni Orang Miskin : Adaptasi Simbolik Terhadap Kemiskinan., ringkasan Disertasi Jakarta: Universitas Indonesia. 1993.

Siswanto, Ari dkk. 1997. Rumah Limas Palembang (Laporan Penelitian). Palembang; Lembaga Penelitian Universitas Sriwijaya.

Soedarso, SP. 2006. Trilogi Seni - Penciptaan, Eksistensi, dan Kegunaan Seni. Yogyakarta: Badan Penerbit ISI Yogyakarta.

Sukanti dan Sudarsono Yus. 1993. Ragam Hias Ukiran pada Rumah Tradisional Sumatera Selatan. Palembang: Museum Negeri Bala putra dewa.

Sugiyono. 2015. Metode Penelitian Pendidikan (Pendekatan Kuantitatif,. Kualitatif dan $R \& D)$. Penerbit CV. Alfabeta: Bandung

Wawancara: Juni Satriawan, Juli 2020. 